\title{
Region-Specific Contribution of the Ventral Tegmental Area to Heroin-Induced Conditioned Immunomodulation
}

\author{
Lee W. Hutson, Jennifer L. Szczytkowski, Timothy B. Saurer, Christina Lebonville, Rita A. \\ Fuchs, and Donald T. Lysle ${ }^{*}$ \\ University of North Carolina at Chapel Hill, Department of Psychology, CB\#3270, Chapel Hill, NC \\ 27599-3270, USA
}

\begin{abstract}
Dopamine receptor stimulation is critical for heroin-conditioned immunomodulation; however, it is unclear whether the ventral tegmental area (VTA) contributes to this phenomenon. Hence, rats received repeated pairings of heroin with placement into a distinct environmental context. At test, they were re-exposed to the previously heroin-paired environment followed by systemic lipopolysaccharide treatment to induce an immune response. Bilateral GABA agonist-induced neural inactivation of the anterior, but not the posterior VTA, prior to context re-exposure inhibited the ability of the heroin-paired environment to suppress peripheral nitric oxide and tumor necrosis factor- $a$ expression, suggesting a role for the anterior VTA in heroin-conditioned immunomodulation.
\end{abstract}

\section{Keywords}

ventral tegmental area; heroin; conditioning; nitric oxide; TNF-a

\section{Introduction}

Opioid administration has detrimental health consequences in addition to the possible development of addictive behaviors and dependence. Clinical studies have revealed abnormalities in basic immune parameters in heroin users, including a decrease in circulating lymphocytes, natural killer cell activity, cytokine production, and antibodydependent cellular cytotoxicity (Govitrapong et al., 1998; Nair et al., 1986; Olson et al., 2005; Yardeni et al., 2008). Several immune parameters that are critical for innate immune responses are altered by opioid use, such as the expression of inducible nitric oxide synthase (iNOS) (Lysle and How, 2000) and the production of the proinflammatory cytokines, tumor necrosis factor- $\alpha$ (TNF- $\alpha$ ), and interleukin-1 $\beta$ (IL-1 $\beta$ ) (Chao et al., 1993; Pacifici et al.,

\footnotetext{
(C) 2014 Elsevier Inc. All rights reserved.

*Corresponding Author: dlysle@email.unc.edu, Telephone: +1-919-537-3748, Fax: +1-919-962-2537.
}

Publisher's Disclaimer: This is a PDF file of an unedited manuscript that has been accepted for publication. As a service to our customers we are providing this early version of the manuscript. The manuscript will undergo copyediting, typesetting, and review of the resulting proof before it is published in its final citable form. Please note that during the production process errors may be discovered which could affect the content, and all legal disclaimers that apply to the journal pertain. 
2000). These studies suggest that chronic opioid administration results in an impaired ability to defend against infectious disease (Theodorou and Haber, 2005).

Interestingly, opioid-induced immunosuppression has been shown to be mediated by the central nervous system (Fecho et al., 1996; Lysle et al., 1996; Shavit et al., 1986), and the immunosuppressive effects of exogenous opioid administration can be conditioned to the context in which the drug is delivered. Indeed, research from our laboratory has shown that the immune altering effects of opioids, including those of morphine and heroin, can be conditioned to environmental stimuli by pairing opioid administration with exposure to a distinct environmental context. As a result, a morphine-paired context can acquire immune altering effects. For example, following conditioning sessions during which morphine injections were paired with a distinct context, rats exhibited significant reductions in mitogenic responsiveness of lymphocytes, natural killer cell activity, and interleukin-2 production when re-exposed to the distinct context in a drug free state, demonstrating for the first time morphine-conditioned immunosuppression (Coussons et al., 1992). These findings are commensurate with other studies exploring the conditioned effects of opiates on other physiological and behavioral processes. For example, the administration of morphine has been shown to results in the development of a conditioned hyperthermia (Broadbent and Cunningham, 1996; Schwarz-Stevens and Cunningham, 1993; Schwarz and Cunningham, 1990). Moreover, exposure to stimuli associated with heroin use has been shown to induce craving for heroin (Daglish et al., 2001; Sell et al., 2000; Zijlstra et al., 2009). Furthermore, contextual stimuli associated drug self-administration has been shown to reinstate heroinseeking behavior (Bossert et al., 2004; Bossert et al., 2012; Fuchs and See, 2002). Thus, the study of conditioning processes has implications for the health consequences of drug use and drug seeking behavior and addiction.

Early evidence suggested that that dopamine and glutamate are involved in conditioned immunomodulation (Hsueh et al., 1999; Kuo et al., 2001). Findings from our laboratory demonstrated that dopamine receptor activity was necessary for the expression of opioidconditioned immune alterations, as administration of a $\mathrm{D}_{1}$-like receptor antagonist prior to re-exposure to a morphine-conditioned stimulus prevented the suppression of natural killer cell activity (Saurer et al., 2008a). Similar immunomodulatory effects have also been demonstrated with heroin (Fecho and Lysle, 2000; Lysle and Ijames, 2002; Saurer et al., 2008a).

Emerging evidence suggests that a limbic neural circuit mediates the expression of heroininduced conditioned immune alterations, and this circuit likely includes the ventral tegmental area (VTA). In support of this, either GABA agonist-induced neural inactivation of, or dopamine $\mathrm{D}_{1}$-like receptor antagonism in, the basolateral amygdala (BLA) blocks heroin-induced conditioned immunosuppression (Szczytkowski and Lysle, 2008, 2010). Moreover, unilateral dopamine $\mathrm{D}_{1}$-like receptor antagonism in the BLA coupled with contralateral NMDA glutamate receptor antagonism in the nucleus accumbens (NAc) shell significantly attenuates the expression of heroin-conditioned immunosuppression (Szczytkowski et al., 2011). In contrast, ipsilateral manipulation of the same brain regions fails to disrupt heroin-conditioned immunomodulation (Szczytkowski et al., 2011). These findings suggest that dopamine in the BLA, via the stimulation of $\mathrm{D}_{1}$-like receptors, is 
necessary for obligatory intrahemispheric interactions between the BLA and the NAc in the control of heroin-conditioned immune alterations.

The critical source of dopamine involved in heroin-conditioned immunomodulation has not been investigated even though the VTA is a likely candidate. Opioid administration has been long believed to result in the disinhibition of dopaminergic projection neurons and the subsequent release of dopamine at terminal regions via the stimulation of $\mu$ opioid receptors on VTA GABAergic inter- and projection neurons (Johnson and North, 1992a). However, recently a revised model has been proposed, in which opioids directly inhibit GABAergic projections from the rostromedial tegmental nucleus to VTA dopamine neurons, thereby suppressing tonic inhibition and resulting in enhanced phasic dopamine activity (Bourdy and Barrot, 2012). Similarly, heroin-associated stimuli increase the activity of VTA neurons (Kiyatkin and Rebec, 2001). Recently, investigations have focused on elucidating the function of various subregions of the VTA, and the findings have suggested that the VTA is a heterogeneous structure with distinct subregions differentially affecting drug-induced behaviors. For example, $\mu$ opioid receptor antagonism in the anterior, but not posterior, VTA prevents the acquisition of cocaine-induced conditioned place preference (Soderman and Unterwald, 2008). Furthermore, rats self-administer the $\mathrm{GABA}_{\mathrm{A}}$ antagonist picrotoxin into the anterior, but not the posterior, VTA (Ikemoto et al., 1997a). A study utilizing retrograde tracing techniques determined that dopaminergic efferents from the VTA to BLA originate in the anterior VTA (Ford et al., 2006), whereas a large proportion of dopaminergic projections from the posterior VTA terminate in the NAc (Ikemoto, 2007). Based on these findings and the importance of dopamine signaling in the BLA in conditioned immunosuppression (Szczytkowski et al., 2011; Szczytkowski and Lysle, 2008, 2010), we hypothesized that the functional integrity of the anterior, but not posterior, VTA is necessary for the expression of heroin-conditioned immunomodulation.

To test this hypothesis, the present study selectively targeted the anterior or posterior VTA in order to evaluate the distinct contributions of these subregions to the expression of heroininduced conditioned immunomodulation. Rats underwent a conditioning procedure which consisted of repeated pairings of heroin administration with placement into a distinct environment. Following the conditioning regimen, rats received microinfusions of saline vehicle or a cocktail of the $\mathrm{GABA}_{\mathrm{B}} / \mathrm{GABA}_{\mathrm{A}}$ agonists, baclofen/muscimol (B/M), into the anterior or posterior VTA to temporarily inactivate these VTA subregions. Rats were then re-exposed to the previously heroin-paired environment in a drug free state. Six hours following re-exposure, rats received a subcutaneous injection of lipopolysaccharide (LPS) to induce an immune response. LPS is a component of the outer cell membrane of Gramnegative bacteria, which activates the innate immune response via the CD14/TLR4/MD-2 complex, resulting in a robust proinflammatory response (Fujihara et al., 2003). To assess context-induced alterations in immune status, the effects of these manipulations were examined on the expression of the proinflammatory mediators, iNOS and TNF-a, in the spleen and/or plasma. 


\section{Materials and Methods}

\subsection{Animals}

Male Lewis rats, weighing 225-250 g, were purchased from Charles River Laboratories (Raleigh, NC, USA). Upon arrival, animals were housed individually in plastic cages in a colony room with a reversed light-dark (12-h) cycle maintained through artificial illumination. Animals were allowed access to food and water ad libitum throughout the experiment except for the time spent in the conditioning chambers when food and water were not available. All animals were given a 2-week habituation period before the start of experimental manipulations and were handled regularly during this time. All procedures described were approved by the IACUC of the University of North Carolina at Chapel Hill and conformed to National Institutes of Health (NIH) Guidelines on the Care and Use of Laboratory Animals.

\subsection{Drug Administration}

Heroin (diacetylmorphine) was obtained from NIDA (Bethesda, MD, USA) and dissolved in $0.9 \%$ sterile saline. Heroin was administered subcutaneously at a dose of $1 \mathrm{mg} / \mathrm{kg}$. This dose was selected based on prior experiments in our laboratory showing that it induces conditioning and alters LPS-induced iNOS and TNF- $a$ mRNA expression in spleen tissue (Lysle and How, 2000; Lysle and Ijames, 2002; Szczytkowski and Lysle, 2007)

\subsection{Surgical Procedures}

Animals were fully anesthetized with $0.35 \mathrm{~mL}$ intramuscular injections of $1: 1$ (vol:vol) ketamine hydrochloride $(100 \mathrm{mg} / \mathrm{mL})$ mixed with xylazine $(20 \mathrm{mg} / \mathrm{mL})$ and placed into the stereotaxic apparatus. Animals were implanted bilaterally with 26-gauge guide cannulae (Plastics One, Roanoke, VA, USA). The cannulae were angled at $10^{\circ}$ and directed towards the anterior VTA (AP $-5.0, \mathrm{ML} \pm 2.2, \mathrm{DV}-6.1 \mathrm{~mm}$, relative to bregma) or posterior VTA (AP $-6.0, \mathrm{ML} \pm 2.1, \mathrm{DV}-6.3 \mathrm{~mm}$, relative to bregma). Animals were given a 2 -week postsurgical recovery period before the start of conditioning trials.

\subsection{Conditioning Procedure}

All animals received five conditioning sessions in standard conditioning chambers (BRS/ LVE, Laurel, MD, USA). Chambers were fitted with a metal grid floor design and cedar bedding to create an environment distinct from that of the home cage and to provide both olfactory and tactile cues for conditioning. Artificial noise machines were used to minimize background noise. All conditioning took place during the dark phase of the light cycle in a room separate from the animal colony and the conditioning chambers were kept dark to minimize effects on circadian rhythms. On each conditioning day, a subcutaneous injection of heroin $(1 \mathrm{mg} / \mathrm{kg})$ was administered immediately prior to placement into the chamber for 60-min. Training sessions were separated by $48 \mathrm{~h}$.

\subsection{Test of Heroin-Conditioned Immunomodulation}

Six days following the final conditioning session, animals received bilateral microinfusions of saline vehicle ( $0.3 \mu \mathrm{L}$ per hemisphere) or $\mathrm{B} / \mathrm{M}(0.3 / 0.03 \mathrm{nmol}$ per $0.3 \mu \mathrm{L}$ per hemisphere) 
into the anterior or posterior VTA. Injectors extended $3 \mathrm{~mm}$ beyond the tip of the guide cannula. Injections were delivered over $1 \mathrm{~min}$, and the injectors were left in place for $1 \mathrm{~min}$ after the injection to allow for proper diffusion of fluid away from the infusion site. Thirty minutes later, the rats were re-exposed to the previously heroin-paired conditioning chamber or remained in their home cages (home cage control groups) for $60 \mathrm{~min}$. Heroin was not administered on the test day in order to isolate the effect of the context on immune responses. After the 60-min time period, all rats received a subcutaneous injection of LPS $(1000 \mu \mathrm{g} / \mathrm{kg})$ and were immediately returned into their home cages. LPS, a component of the cell wall of Gram negative bacteria, was used to induce iNOS and TNF-a production. Prior work from our laboratory has determined the dose and route of delivery used in the present study to be effective in generating a robust proinflammatory response (Szczytkowski et al., 2011; Szczytkowski and Lysle, 2007, 2008, 2010) Six hours after LPS administration, all animals were euthanized. The 6-h time point was selected based on previous research in our laboratory showing maximal iNOS induction $6 \mathrm{~h}$ following LPS administration (Lysle and How, 2000).

\subsection{Histology}

Samples of spleen and blood were collected for analysis. Spleen samples were either stored in an Ambion ${ }^{\circledR}$ RNA Later solution or Roche complete protease inhibitor cocktail solution. To confirm proper cannula placement, Alcian blue dye was infused via the cannula. Brains were then extracted and post-fixed in a $4 \%$ paraformaldehyde solution. Following fixation the brains were transferred to a $30 \%$ sucrose solution for cryoprotection and then frozen at $-80{ }^{\circ} \mathrm{C}$ until further analysis. Coronal sections $(40 \mu \mathrm{m})$ were taken and stained with cresyl violet for verification of cannula placement. The data of animals with cannula placement outside of the targeted region were removed from subsequent data analyses.

\subsection{Real-Time qRT-PCR}

To determine iNOS and TNF- $a$ expression, real time RT-PCR was performed on tissue samples from the spleen. Total RNA was extracted from a section of each of the tissues using TRI-Reagent (Molecular Research Center, Cincinnati, OH), a modification of the original method described by Chomczynski and Sacchi (1987). RNA was quantified spectrophotometrically (GeneQuant II, Pharmacia-Biotech, Piscataway, NJ, USA). Reverse transcription was performed using Oligo $(\mathrm{dT})_{18}$ primer and Moloney Murine Leukemia Virus-Reverse transcriptase following the protocol of the Advantage RT-for-PCR Kit from Clontech (Palo Alto, CA, USA). Specific products from the PCR reaction were detected with Universal ProbeLibrary Probes (Roche, Indianapolis, IN). PCR amplifications were performed using standard protocols, the LightCycler TaqMan Master Real-Time PCR Kit, and the LightCycler II instrument (Roche, Indianapolis, IN). A master mix containing all reaction components was prepared and then $20 \mu \mathrm{l}$ of cDNA with master mix was placed in glass capillary tubes designed for use in the LightCycler II system. Primers and probes for immune parameters were as follows: (iNOS) $5^{\prime}$-TGAGGATTACTTCTTCCAGCTCA-3' and $5^{\prime}$-TGGGTGTCAGAGTCTTGTGC-3' ${ }^{\prime}$, using probe \#25; (TNF-a) $5^{\prime}$ GGGCCTCCAGAACTCCAG-3' and 5'-GAGCCATTTGGGAACTTCT-3' ${ }^{\prime}$, using probe \#98. Primers were synthesized by the Nucleic Acids Core Facility (Lineberger Cancer Center, UNC-Chapel Hill). Copy numbers were generated based on an internal standard 
curve. Amplifications were carried out for 45 cycles and curves showing fluorescence at each cycle were determined by the computer software (Roche). Samples were pre-incubated for $10 \mathrm{~min}$ at $95^{\circ} \mathrm{C}$ to activate the Fast-Start Taq DNA polymerase. The cycle temperatures were 95 and $60{ }^{\circ} \mathrm{C}$ and the cycle times were 10 and $30 \mathrm{~s}$ for the denaturing and annealing/ extending, respectively. Fluorescence level was determined at the end of the extending phase for each cycle of PCR. A final cooling phase was carried out at $40^{\circ} \mathrm{C}$ for $30 \mathrm{~s}$. The analysis of the fluorescence in standards and samples over the course of 45 cycles was used to derive the number of copies of the target molecule in each sample. Additionally, assessments of housekeeping gene expression, L13A, were made to verify comparable RNA quality of among samples. L13A primers were $5^{\prime}$-CCCTCCACCCTATGACAAGA- $3^{\prime}$ and $5^{\prime}$-GGTACTTCCACCCGACCTC- $3^{\prime}$, using probe \#74. The data are expressed as copy numbers.

\subsection{Nitrite/Nitrate Assay}

The nitrite/nitrate concentration in plasma samples was assessed using the Greiss reagent assay described previously (Szczytkowski and Lysle, 2007). Briefly, $6 \mu$ of plasma was diluted in $44 \mu \mathrm{l}$ of $\mathrm{dH} 2 \mathrm{O}$, and the sample was incubated in the dark for 90 min with $10 \mu \mathrm{l}$ of nitrate reductase $(1.0 \mathrm{U} / \mathrm{ml}), 20 \mu \mathrm{l}$ of $0.31 \mathrm{M}$ phosphate buffer $(\mathrm{pH} 7.5), 10 \mu \mathrm{l}$ of $0.86 \mathrm{mM}$ NADPH (Sigma), and $10 \mu \mathrm{l}$ of $0.11 \mathrm{mM}$ flavin adenine dinucleotide in individual wells of a 96-well plate. Next, $200 \mathrm{ml}$ of Greiss reagent, consisting of a 1:1 (v/v) solution 1\% sulfanilamide in $5.0 \%$ phosphoric acid and $0.1 \% \mathrm{~N}$-(1-napthyl) ethyl-enedamine dihydrochloride in distilled water, was added to the samples. The color was allowed to develop for $10 \mathrm{~min}$ at room temperature, after which, the absorbance was determined using a spectrophotometer set at $550 \mathrm{~nm}$. All reactions were carried out in triplicate. The total micromolar concentration of nitrite was determined for each sample based on a standard curve. Recovery of nitrate is greater than $95 \%$ using this assay.

\subsection{ELISA}

To assess TNF-a protein expression, protein was extracted from homogenized tissue using freeze/thaw lysis in tris-buffer containing antiproteinases. Protein was quantified spectrophotometrically (Bio-Tek, $\mu$ Quant Monochromatic Microplate Spectrophotometer, Winooski, VT, USA) using Bio-Rad protein dye. Samples were normalized per unit protein based on spectrophotometric analysis. Invitrogen (Carlsbad, CA) rat TNF-a ELISA test kits were used to determine the levels of TNF- $a$ protein in each tissue sample. The samples were processed following the kit manufacturer's protocol. Sample concentrations were determined based on plotting absorbance against the concentrations of supplied standards.

\subsection{Statistical Analysis}

Two-way analysis of variance was performed on all data sets. The first factor was test context, which compared re-exposure to the conditioned environment to home cage groups, and the second factor was inactivation treatment, comparing VTA inactivation with B/M or saline. Post-hoc analyses were performed using Fisher's Least Significant Difference tests. All analyses were conducted with alpha set at $p<0.05$. Only significant interactions and main effects are reported. 


\section{Results}

\subsection{Anterior VTA Inactivation}

Figure 1A shows the effect of anterior VTA inactivation on LPS-induced heroin-conditioned iNOS mRNA expression in spleen tissue following exposure to the heroin-paired context or the home cage. The ANOVA of iNOS mRNA copy numbers revealed a significant context by treatment interaction effect $[F(1,16)=14.88, P<0.005]$. Post-hoc analyses revealed that saline-treated rats exposed to the heroin-paired context exhibited a significant reduction in iNOS mRNA expression compared to that in the home cage. In contrast, rats that received intra-VTA microinjections of B/M failed to exhibit differences in iNOS mRNA expression after exposure to the previously heroin-paired environment or the home cage. There were also no differences across groups in housekeeping gene expression (data not shown).

Figure 1B shows the effect of anterior VTA inactivation on LPS-induced plasma nitrate/ nitrite levels. The ANOVA of nitrate/nitrite levels revealed a significant context by treatment interaction effect $[F(1,16)=5.83, P<0.05]$. Post-hoc analyses revealed that saline-treated rats exposed to the heroin-paired context exhibited a significant reduction in iNOS mRNA expression compared to that in the home cage. Rats that received intra-VTA microinjections of B/M failed to exhibit differences in iNOS mRNA expression after exposure to the two contexts and compared to the saline-treated home cage control group.

Figure 2 shows the effect of anterior VTA inactivation on LPS-induced TNF- $a$ mRNA and protein expression. The ANOVA found a significant context by treatment interaction effect for TNF-a mRNA expression $[F(1,16)=6.46 P<0.05]$ and TNF-a protein levels $[F(1,15)$ $=4.57, P<0.05]$. Post-hoc analyses revealed that saline-treated rats exposed to the heroinpaired context exhibited a significant reduction in TNF-a mRNA expression and protein levels compared to home cage animals. By comparison, animals that underwent anterior VTA inactivation prior to context re-exposure showed no significant difference in LPSinduced TNF- $a$ mRNA expression or protein levels compared to anterior VTA saline infused controls. No differences in housekeeping gene expression were observed across groups (data not shown).

\subsection{Posterior VTA Inactivation}

Figure 3A shows the effect of posterior VTA inactivation on LPS-induced iNOS mRNA expression. Analysis revealed a significant context main effect only $[F(1,15)=20.32, P<$ $0.0001]$. Thus, context re-exposure produced a similar decrease in iNOS mRNA expression in the posterior VTA inactivated and control groups, relative to home cage exposure.

Figure 3B shows the effect of posterior VTA inactivation on LPS-induced nitrate/nitrite levels in blood plasma. The ANOVA also revealed a context significant main effect only $[F(1,15)=7.28, P<0.05]$. Therefore, context re-exposure produced a similar decrease in nitrate/nitrite levels in the posterior VTA inactivated and control groups, relative to home cage exposure.

Figure 4A shows the effect of posterior VTA inactivation on LPS-induced TNF-a mRNA expression. The ANOVA of TNF-a mRNA expression revealed a marginally significant 
main effect of context $[F(1,14)=4.22, P=0.059]$. Thus, context re-exposure produced a similar decrease in $n$ TNF- $a$ mRNA expression in the posterior VTA inactivated and control groups, relative to home cage exposure.

Figure 4B shows the effect of posterior VTA inactivation on LPS-induced TNF-a protein levels. The ANOVA of TNF-a protein levels revealed significant context $[F(1,15)=14.68$, $P<0.005]$ and drug treatment main $[F(1,15)=10.12, P<0.01]$ effects. Thus, the posterior VTA inactivated group exhibited lower TNF-a protein levels than the saline control group. However, context re-exposure produced a similar decrease in $n$ TNF- $a$ mRNA expression in the posterior VTA inactivated and control groups, relative to home cage exposure.

\section{Discussion}

In the present study, neural activity in the anterior or posterior VTA was inhibited using GABA agonists prior to re-exposure to a heroin-paired environmental context in order to determine whether subregions of the VTA play different roles in the expression of heroinconditioned immune alterations. Anterior VTA neuronal inactivation disrupted the immunosuppressive effects of the heroin-paired context on LPS-induced TNF- $a$ and iNOS expression. This suggests that the functional integrity of the anterior VTA is necessary for the expression of heroin-induced conditioned immune suppression of proinflammatory mediators. In marked contrast, posterior VTA inactivation failed to alter heroin-paired context-induced alterations of proinflammatory mediators even though it produced a context-independent reduction in TNF-a protein levels. Overall, this pattern of findings suggests that the anterior VTA, but not the posterior VTA, has a critical role in heroininduced conditioned immune alterations. These findings expand our understanding of the neural circuitry involved in heroin-conditioned immunomodulation by identifying a source of dopamine that alters the activity of several other brain regions within the mesolimbic dopamine system, as well as provide insight into the neural mechanisms of drugs of abuse.

Previous research in our laboratory suggests that dopamine regulates multiple elements of the neural circuitry underlying conditioned immunomodulation. In support of this, inactivation of the BLA and blockade of dopamine $\mathrm{D}_{1}$-like receptors within the BLA prevent the suppressive effect of the heroin-associated context on iNOS induction and on TNF- $\alpha$ and IL- $1 \beta$ expression in spleen and liver tissue (Szczytkowski and Lysle, 2008, 2010). Dopamine $D_{1}$-like receptor antagonism in the NAc shell blocks the expression of morphine-induced conditioned immune alterations (Saurer et al., 2008b). In a recent functional disconnection study from our laboratory (Szczytkowski et al., 2011), we provided evidence that the NAc plays a critical role in heron-conditioned immunomodulation as an element of a larger VTA-BLA-NAc circuit. In that study, rats received unilateral administration of the $\mathrm{D}_{1}$-like dopamine antagonist, $\mathrm{SCH} 23390$, in the BLA in combination with unilateral administration of the NMDA or AMPA/kainate antagonist, into the ipsilateral or contralateral NAc on test day. Contralateral manipulation (i.e., disconnection) of the VTA-BLA-NAc circuit inhibited the heroin-conditioned immunosuppression of iNOS and TNF- $a$ expression in the spleen. Conversely, the ipsilateral manipulation, which left intrahemispheric information processing between the BLA and NAc intact in one hemisphere, failed to alter proinflammatory responses. Given that the VTA is one of the 
primary sources of dopamine to the BLA (Rosenkranz and Grace, 1999), these findings suggest that serial information processing via a VTA-BLA-NAc circuit is necessary for the expression of heroin-conditioned immunomodulation. However, the direct role of the VTA and the subregions of the VTA in conditioned heroin effects had not been investigated prior to this study.

There are studies, consistent with the present findings, demonstrating functional differences between subregions of the VTA, as microinfusions of the $\mathrm{GABA}_{\mathrm{A}}$ agonist muscimol into the anterior, but not posterior VTA, significantly reduced cocaine self-administration (Lee et al., 2007). Furthermore, rats will self-administer the $\mathrm{GABA}_{\mathrm{A}}$ receptor antagonist picrotoxin into the anterior, but not the posterior, VTA (Ikemoto et al., 1997b). This effect may be mediated by the disinhibition of dopaminergic neurons in the anterior VTA and subsequent dopamine release in the NAc since picrotoxin administration into the anterior VTA increases dopamine overflow in the NAc (Ikemoto et al., 1997a). Functional differences between anterior and posterior VTA subregions reflect differences in neurochemistry and connectivity between these VTA subregions (Johnson and North, 1992b; Swanson, 1982). For example, the anterior and posterior VTA contain different proportions of dopaminergic and glutamatergic neurons and GABAergic interneurons, with a higher proportion of GABAergic interneurons and dopaminergic neurons located in the anterior VTA and posterior VTA, respectively (Olson et al., 2005; Yamaguchi et al., 2007). Interestingly, VTA efferents to the BLA are localized in the anterior VTA, which was verified using retrograde tracing techniques (Ford et al., 2006; Ikemoto, 2007). Conversely, dopamine neurons from the posterior VTA project to NAc core and medial shell, with a significant amount of overlap in projections between the anterior and posterior VTA.

Given the previously discussed importance of dopamine in the BLA in heroin-conditioned immunosuppression, we hypothesized that the anterior, but not posterior, VTA would be important in the expression of heroin-conditioned immunomodulation. The results of the present study support this hypothesis. Our findings also suggest that projections from the posterior VTA, which include projections to the NAc shell and core, are not critical for the expression of the observed heroin-conditioned suppression of proinflammatory mediators. On the other hand, dopaminergic signaling to the NAc originating from the anterior VTA may play a role in heroin-conditioned immunosuppression. Importantly, interactions between the VTA, NAc, and BLA appear to be complex, as dopamine release in the NAc is proposed to be regulated by BLA glutamatergic efferents (Jones et al., 2010). Consistent with this, temporary neural inactivation of the BLA results in decreased discriminative stimulus-induced evoked NAc dopamine release. In addition, BLA inactivation has no effect on NAc dopamine release following VTA stimulation, indicating that the BLA does not modulate dopamine release indirectly through the VTA (Howland et al., 2002). Taken together, these previous findings suggest that dopaminergic signaling from the anterior VTA may result in dopamine release at the terminal level in the NAc.

The present studies do not address the inputs responsible for the activation of the VTA. In other studies, we have demonstrated that inactivation of the dorsal hippocampus prevents heroin-conditioned immunosuppression of LPS-induced nitric oxide production (Szczytkowski et al., 2013). Furthermore, a recent study demonstrated that a bi-synaptic 
functional circuit conveys information from the CA3 region of the dorsal hippocampus to the anterior VTA via the lateral septum (LS). As a result, GABA agonist-induced inactivation of the LS attenuates excitatory and inhibitory neuronal firing in the VTA following CA3 stimulation. In addition, inactivation of the CA3, as well as the LS, impairs drug context-induced reinstatement of cocaine-seeking behavior (Luo et al., 2011). These findings suggest that activation of CA3 glutamatergic pyramidal neurons results in the disinhibition of VTA dopamine neurons via this circuit, thus contributing to the expression of context-reward associations. It is possible that similar mechanisms play a role in heroinconditioned immunomodulation.

In conclusion, the present study demonstrates that GABA agonist-induced inactivation of the anterior, but not posterior, VTA blocks heroin-conditioned immunosuppression of iNOS induction and the expression of TNF- $a$ in spleen tissue. Taken together with previous findings, these results enhance our understanding of the neural circuit involved in the conditioned effects of heroin on immune function, further elucidating the mechanisms responsible for increased susceptibility to infections associated with heroin-conditioned contextual stimuli, as well as contributing to the understanding drug reward conditioning neural circuitry.

\section{Acknowledgments}

Jennifer L. Szczytkowski is now at Messiah College, Department of Psychology, One College Avenue Suite 3052, Mechanicsburg, PA 17055 USA. This research was supported by National Institute on Drug Abuse grant DA25667 and the National Institutes of Health, Training, Workforce Development, and Diversity division of the National Institute of General Medical Sciences (NIGMS) grant K12GM000678.

\section{References}

Bossert JM, Liu SY, Lu L, Shaham Y. A role of ventral tegmental area glutamate in contextual cueinduced relapse to heroin seeking. J Neurosci. 2004; 24:10726-10730. [PubMed: 15564590]

Bossert JM, Stern AL, Theberge FR, Marchant NJ, Wang HL, Morales M, Shaham Y. Role of projections from ventral medial prefrontal cortex to nucleus accumbens shell in context-induced reinstatement of heroin seeking. J Neurosci. 2012; 32:4982-4991. [PubMed: 22492053]

Bourdy R, Barrot M. A new control center for dopaminergic systems: pulling the VTA by the tail. Trends in neurosciences. 2012; 35:681-690. [PubMed: 22824232]

Broadbent J, Cunningham CL. Pavlovian conditioning of morphine hyperthermia: assessment of interstimulus interval and CS-US overlap. Psychopharmacology. 1996; 126:156-164. [PubMed: 8856835]

Chao C, Molitor T, Close K, Hu S, Peterson P. Morphine inhibits the release of tumor necrosis factor in human peripheral blood mononuclear cell cultures. Int J Immunopharmacol. 1993; 15:447-453. [PubMed: 8389331]

Coussons ME, Dykstra LA, Lysle DT. Pavlovian conditioning of morphine-induced alterations of immune status. Journal of neuroimmunology. 1992; 39:219-230. [PubMed: 1644897]

Daglish MR, Weinstein A, Malizia AL, Wilson S, Melichar JK, Britten S, Brewer C, Lingford-Hughes A, Myles JS, Grasby P, Nutt DJ. Changes in regional cerebral blood flow elicited by craving memories in abstinent opiate-dependent subjects. The American journal of psychiatry. 2001; 158:1680-1686. [PubMed: 11579002]

Fecho K, Lysle DT. Heroin-induced alterations in leukocyte numbers and apoptosis in the rat spleen. Cellular immunology. 2000; 202:113-123. [PubMed: 10896771] 
Fecho K, Maslonek KA, Dykstra LA, Lysle DT. Assessment of the involvement of central nervous system and peripheral opioid receptors in the immunomodulatory effects of acute morphine treatment in rats. J Pharmacol Exp Ther. 1996; 276:626-636. [PubMed: 8632330]

Ford C, Mark G, Williams J. Properties and opioid inhibition of mesolimbic dopamine neurons vary according to target location. The Journal of neuroscience : the official journal of the Society for Neuroscience. 2006; 26:2788-2797. [PubMed: 16525058]

Fuchs RA, See RE. Basolateral amygdala inactivation abolishes conditioned stimulus- and heroininduced reinstatement of extinguished heroin-seeking behavior in rats. Psychopharmacology. 2002; 160:425-433. [PubMed: 11919670]

Fujihara M, Muroi M, Tanamoto K, Suzuki T, Azuma H, Ikeda H. Molecular mechanisms of macrophage activation and deactivation by lipopolysaccharide: roles of the receptor complex. Pharmacology \& therapeutics. 2003; 100:171-194. [PubMed: 14609719]

Govitrapong P, Suttitum T, Kotchabhakdi N, Uneklabh T. Alterations of immune functions in heroin addicts and heroin withdrawal subjects. J Pharmacol Exp Ther. 1998; 286:883-889. [PubMed: 9694946]

Howland J, Taepavarapruk P, Phillips A. Glutamate receptor-dependent modulation of dopamine efflux in the nucleus accumbens by basolateral, but not central, nucleus of the amygdala in rats. $\mathrm{J}$ Neurosci. 2002; 22:1137-1145. [PubMed: 11826142]

Hsueh CM, Kuo JS, Chen SF, Huang HJ, Cheng FC, Chung LJ, Lin RJ. Involvement of catecholamines in recall of the conditioned NK cell response. Journal of neuroimmunology. 1999; 94:172-181. [PubMed: 10376951]

Ikemoto S. Dopamine reward circuitry: two projection systems from the ventral midbrain to the nucleus accumbens-olfactory tubercle complex. Brain research reviews. 2007; 56:27-78. [PubMed: 17574681]

Ikemoto S, Kohl R, McBride W. GABA(A) receptor blockade in the anterior ventral tegmental area increases extracellular levels of dopamine in the nucleus accumbens of rats. Journal of neurochemistry. 1997a; 69:137-143. [PubMed: 9202304]

Ikemoto S, Murphy J, McBride W. Self-infusion of GABA(A) antagonists directly into the ventral tegmental area and adjacent regions. Behav Neurosci. 1997b; 111:369-380. [PubMed: 9106676]

Johnson SW, North RA. Opioids excite dopamine neurons by hyperpolarization of local interneurons. J Neurosci. 1992a; 12:483-488. [PubMed: 1346804]

Johnson SW, North RA. Two types of neurone in the rat ventral tegmental area and their synaptic inputs. The Journal of physiology. 1992b; 450:455-468. [PubMed: 1331427]

Jones J, Day J, Aragona B, Wheeler R, Wightman R, Carelli R. Basolateral amygdala modulates terminal dopamine release in the nucleus accumbens and conditioned responding. Biological Psychiatry. 2010; 67:737-744. [PubMed: 20044074]

Kiyatkin E, Rebec G. Impulse activity of ventral tegmental area neurons during heroin selfadministration in rats. Neuroscience. 2001; 102:565-580. [PubMed: 11226694]

Kuo JS, Chen SF, Huang HJ, Yang CS, Tsai PJ, Hsueh CM. The involvement of glutamate in recall of the conditioned NK cell response. Journal of neuroimmunology. 2001; 118:245-255. [PubMed: 11498259]

Lee D, Guttilla M, Fung K, McFeron S, Yan J, Ranaldi R. Rostral-caudal differences in the effects of intra-VTA muscimol on cocaine self-administration. Pharmacol Biochem Behav. 2007; 86:542549. [PubMed: 17291573]

Luo AH, Tahsili-Fahadan P, Wise RA, Lupica CR, Aston-Jones G. Linking context with reward: a functional circuit from hippocampal CA3 to ventral tegmental area. Science. 2011; 333:353-357. [PubMed: 21764750]

Lysle DT, Hoffman KE, Dykstra LA. Evidence for the involvement of the caudal region of the periaqueductal gray in a subset of morphine-induced alterations of immune status. J Pharmacol Exp Ther. 1996; 277:1533-1540. [PubMed: 8667220]

Lysle DT, How T. Heroin modulates the expression of inducible nitric oxide synthase. Immunopharmacology. 2000; 46:181-192. [PubMed: 10741899]

Lysle DT, Ijames SG. Heroin-associated environmental stimuli modulate the expression of inducible nitric oxide synthase in the rat. Psychopharmacology. 2002; 164:416-422. [PubMed: 12457272] 
Nair NK, Navaratnam V, Rajananda V. Analysis of illicit heroin. I. An effective thin-layer chromatographic system for separating eight opiates and five adulterants. Journal of chromatography. 1986; 366:363-372. [PubMed: 3782326]

Olson V, Zabetian C, Bolanos C, Edwards S, Barrot M, Eisch A, Hughes T, Self D, Neve R, Nestler E. Regulation of drug reward by cAMP response element-binding protein: evidence for two functionally distinct subregions of the ventral tegmental area. J Neurosci. 2005; 25:5553-5562. [PubMed: 15944383]

Pacifici R, di Carlo S, Bacosi A, Pichini S, Zuccaro P. Pharmacokinetics and cytokine production in heroin and morphine-treated mice. Int J Immunopharmacol. 2000; 22:603-614. [PubMed: 10988355]

Rosenkranz JA, Grace AA. Modulation of basolateral amygdala neuronal firing and afferent drive by dopamine receptor activation in vivo. J Neurosci. 1999; 19:11027-11039. [PubMed: 10594083]

Saurer T, Ijames S, Carrigan K, Lysle D. Neuroimmune mechanisms of opioid-mediated conditioned immunomodulation. Brain, behavior, and immunity. 2008a; 22:89-97.

Saurer TB, James SG, Carrigan KA, Lysle DT. Neuroimmune mechanisms of opioid-mediated conditioned immunomodulation. Brain Behav Immun. 2008b; 22:89-97. [PubMed: 17689049]

Schwarz-Stevens KS, Cunningham CL. Pavlovian conditioning of heart rate and body temperature with morphine: effects of CS duration. Behav Neurosci. 1993; 107:1039-1048. [PubMed: 8136057]

Schwarz KS, Cunningham CL. Conditioned stimulus control of morphine hyperthermia. Psychopharmacology. 1990; 101:77-84. [PubMed: 2343076]

Sell LA, Morris JS, Bearn J, Frackowiak RS, Friston KJ, Dolan RJ. Neural responses associated with cue evoked emotional states and heroin in opiate addicts. Drug and alcohol dependence. 2000; 60:207-216. [PubMed: 10940548]

Shavit Y, Depaulis A, Martin FC, Terman GW, Pechnick RN, Zane CJ, Gale RP, Liebeskind JC. Involvement of brain opiate receptors in the immune-suppressive effect of morphine. Proceedings of the National Academy of Sciences of the United States of America. 1986; 83:7114-7117. [PubMed: 3018757]

Soderman A, Unterwald E. Cocaine reward and hyperactivity in the rat: sites of mu opioid receptor modulation. Neuroscience. 2008; 154:1506-1516. [PubMed: 18550291]

Swanson LW. The projections of the ventral tegmental area and adjacent regions: a combined fluorescent retrograde tracer and immunofluorescence study in the rat. Brain research bulletin. 1982; 9:321-353. [PubMed: 6816390]

Szczytkowski JL, Fuchs RA, Lysle DT. Ventral tegmental area-basolateral amygdala-nucleus accumbens shell neurocircuitry controls the expression of heroin-conditioned immunomodulation. Journal of neuroimmunology. 2011; 237:47-56. [PubMed: 21722970]

Szczytkowski JL, Lebonville C, Hutson L, Fuchs RA, Lysle DT. Heroin-induced conditioned immunomodulation requires expression of IL-1beta in the dorsal hippocampus. Brain Behav Immun. 2013; 30:95-102. [PubMed: 23357470]

Szczytkowski JL, Lysle DT. Conditioned effects of heroin on the expression of inducible nitric oxide synthase in the rat are susceptible to extinction and latent inhibition. Psychopharmacology. 2007; 191:879-889. [PubMed: 17211650]

Szczytkowski JL, Lysle DT. Conditioned effects of heroin on proinflammatory mediators require the basolateral amygdala. The European journal of neuroscience. 2008; 28:1867-1876. [PubMed: 18973600]

Szczytkowski JL, Lysle DT. Dopamine D1 receptors within the basolateral amygdala mediate heroininduced conditioned immunomodulation. Journal of neuroimmunology. 2010; 226:38-47. [PubMed: 20605224]

Theodorou S, Haber PS. The medical complications of heroin use. Current opinion in psychiatry. 2005; 18:257-263. [PubMed: 16639149]

Yamaguchi T, Sheen W, Morales M. Glutamatergic neurons are present in the rat ventral tegmental area. Eur J Neurosci. 2007; 25:106-118. [PubMed: 17241272] 
Yardeni IZ, Beilin B, Mayburd E, Alcalay Y, Bessler H. Relationship between fentanyl dosage and immune function in the postoperative period. Journal of opioid management. 2008; 4:27-33. [PubMed: 18444445]

Zijlstra F, Veltman DJ, Booij J, van den Brink W, Franken IH. Neurobiological substrates of cueelicited craving and anhedonia in recently abstinent opioid-dependent males. Drug and alcohol dependence. 2009; 99:183-192. [PubMed: 18823721] 
A

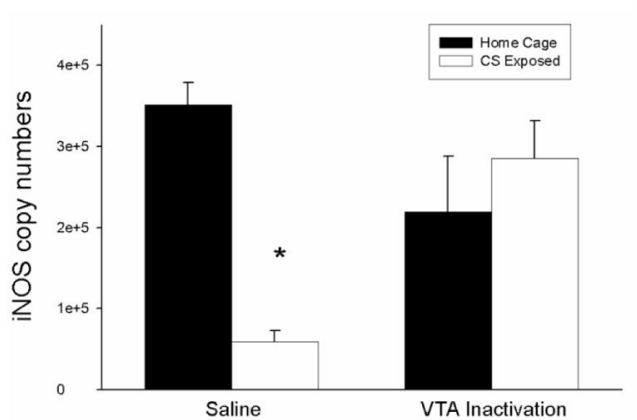

B

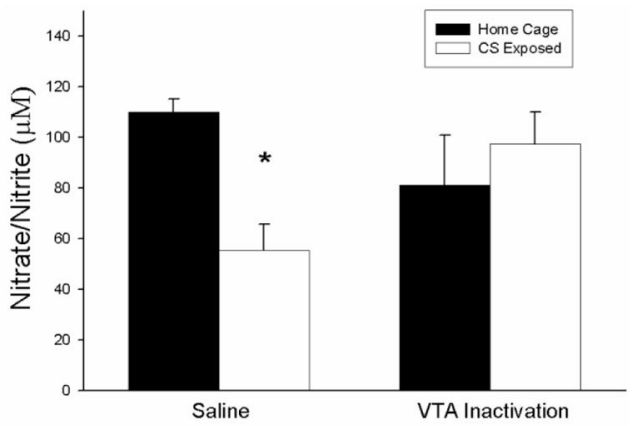

Figure 1.

Effects of context re-exposure and B/M-induced inactivation of the anterior VTA on LPSinduced: (A) expression of iNOS mRNA as determined by real-time RT-PCR. The data are expressed as iNOS copy number per 10ng cDNA based on a standard curve using Roche LightCycler software. (B) nitrate/nitrite serum levels as determined by Greiss Reagent Assay. The data are expressed as the mean micromolar concentration of nitrite/nitrate. The error bars represent the standard error of the mean. There was a significant interaction between context and inactivation and post-hoc analysis compared context re-exposure and home cage within inactivation treatment ( $*$ indicates post hoc comparison $\mathrm{p}<.05$ ). 
A

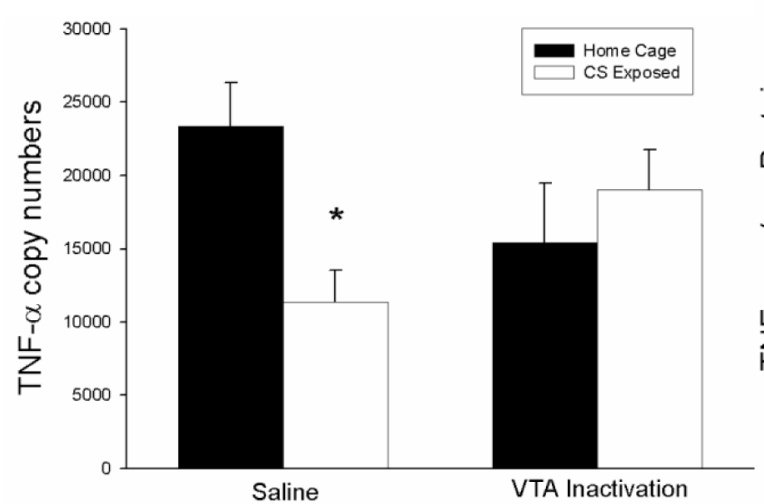

B

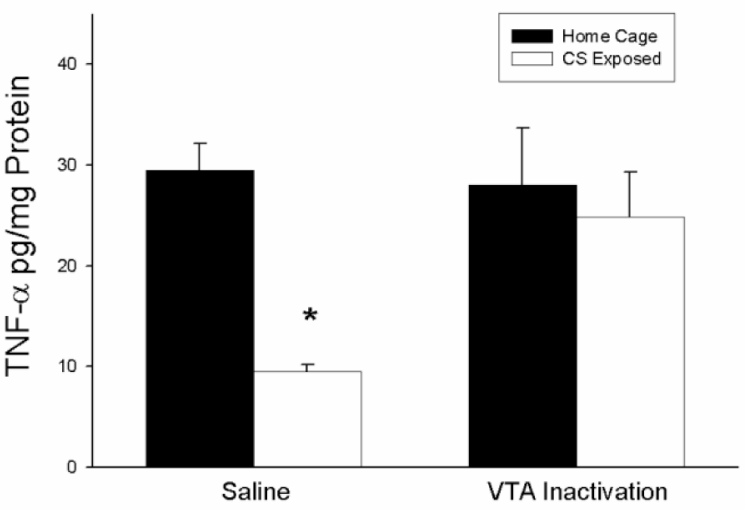

Figure 2.

Effects of context re-exposure and B/M-induced inactivation of the anterior VTA on LPSinduced: (A) expression of TNF- $a$ mRNA determined by real-time RT-PCR. The data are expressed as TNF- $a$ copy number per 10ng cDNA based on a standard curve using Roche LightCycler software. (B) production of TNF- $a$ protein determined by ELISA. The data are expressed as picograms of protein per $\mathrm{ml}$. The error bars represent the standard error of the mean. There was a significant interaction between context and inactivation and post-hoc analysis compared context re-exposure and home cage within inactivation treatment $(*$ indicates post hoc comparison $\mathrm{p}<.05$ ). 
A

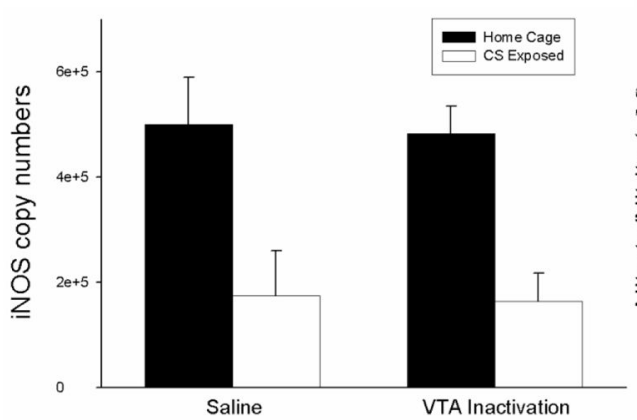

B

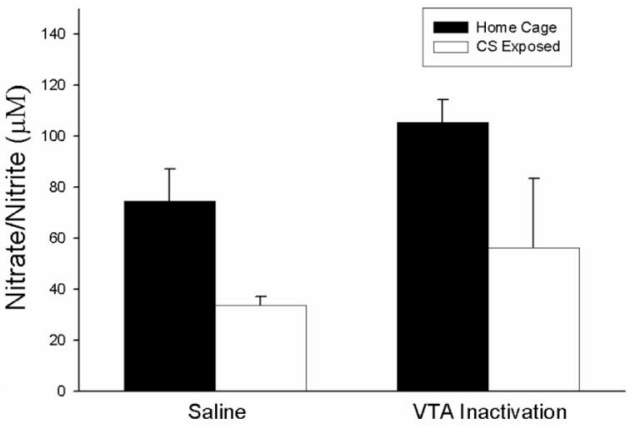

Figure 3.

Effects of context re-exposure and B/M-induced inactivation of the posterior VTA on LPSinduced: (A) expression of iNOS mRNA as determined by real-time RT-PCR. The data are expressed as iNOS copy number per 10ng cDNA based on a standard curve using Roche LightCycler software. (B) nitrate/nitrite serum levels as determined by Greiss Reagent Assay. The data are expressed as the mean micromolar concentration of nitrite/nitrate. The error bars represent the standard error of the mean. The analysis showed a main effect of context for both iNOS mRNA and serum levels of nitrate/nitrite $(\mathrm{p}<.05)$, but no significant interaction with inactivation. 
A

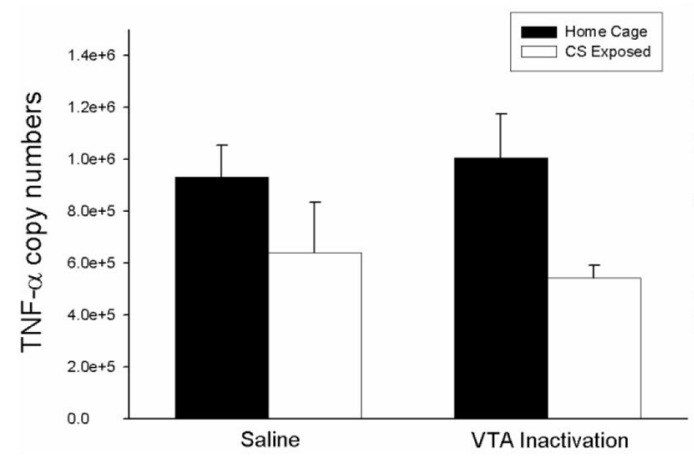

B

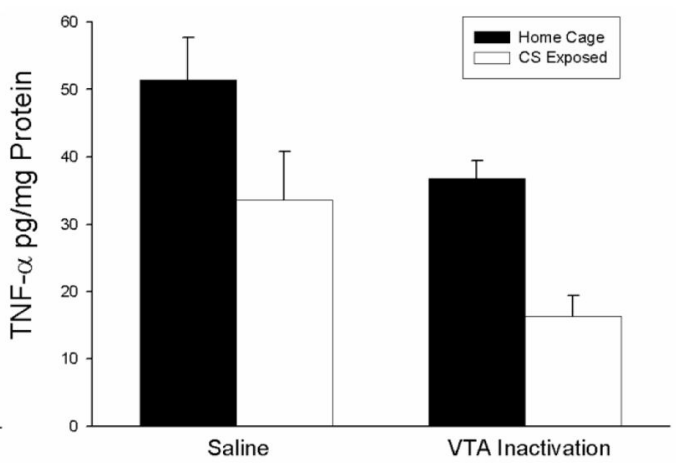

Figure 4.

Effects of context re-exposure and B/M-induced inactivation of the posterior VTA on LPSinduced: (A) expression of TNF-a mRNA determined by real-time RT-PCR. The data are expressed as TNF-a copy number per 10ng cDNA based on a standard curve using Roche LightCycler software. (B) production of TNF-a protein determined by ELISA. The data are expressed as pictograms of protein per $\mathrm{ml}$. The error bars represent the standard error of the mean. The analysis showed a main effect of context $(\mathrm{p}<.05)$ for both mRNA and protein. There was also a main effect of inactivation for TNF- $a$ protein $(p<.05)$. There was no significant interaction between context and inactivation. 